certainly not suffering from "purpura rheumatica"-indeed the skin lesions described ("the eruption . . . consisted of irregular diffused patches, somewhat raised, and of a bright red colour; they were chiefly on the outside of the calf, as low down as the ankle") are typical of erythema nodosum. Johnson describes this as "a purpuric eruption." I cannot find, in the 34 other cases which Johnson carefully describes, any features suggestive of kidney disease associated with purpura rheumatica.

Schönlein, ${ }^{3}$ on the other hand, clearly did recognize urinary abnormalities in purpura rheumatica. The bibliographical details of his Allgemeine und speciclle $\mathrm{Pa}$ hologie und Therapie are a little obscure, since it appears to have been compiled by students from lecture notes without his authorization. At least one of the editions was disowned by him. ${ }^{5}$ However, in all the editions which I have been able to consult the description of "peliosis rheumatica" ( = purpura rheumatica) contains the phrase: "Nicht selten Ausscheidungen im Harne" ("frequently precipitates [occur] in the urine"). The contribution of Henoch is less in doubt. In $1868^{6}$ (not in 1874, as quoted by Meadow $e$ : $a l .{ }^{7}$ ) he first drew attention to the gastrointestinal manifestations of purpura rheumatica. Meadow et al. draw attention to a boy described by Heberden in the posthumously published "Commentaries" of $1801^{8}$ (not 1806), which clearly illustrates the same disease.

There are two conclusions to be drawn. The first is that Schönlein has a better case than Johnson to be considered the first to d-scribe renal involvement in purpura rheumatica. Johnson, in fact, used "purpura" to describe lesions which would certainly not be considered purpuric today. The second conclusion is that those who write historical introductions to their articles might find it entertaining, and even, occasionally, useful, to spend a little time reading the authors to whom they refer.-I am, etc.,

\section{Southmead Hospital,}

J. VERRIER JONES

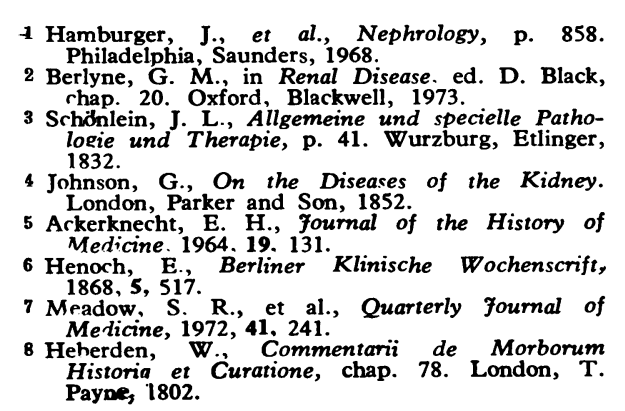

\section{Diabetic Pregnancy}

SIR,-In commenting on our paper on diabetic pregnancy (13 October, p. 89) Dr. M. I. Drury (10 November, p. 358) asks: (1) how many terminations of pregnancy were performed on our patients and (2) why our series included fewer cases of diabetes diagnosed during pregnancy than his own and others.

(1) In 1971-2, when 77 diabetic women were delivered at this hospital, there were four terminations of pregnancy in diabetics. Two of the women, aged 16 and 20 , were unmarried and pregnancy was ter- minated for social reasons. The third, also unmarried, had chronic active hepatitis treated with prednisone and azathioprine. She later married and had a successful pregnancy. The fourth, a Jamaican woman aged 39 with mild diabetes treated with chlorpropamide, had had four children and suffered from depression. All asked for termination; in none was there any diabetic complication.

(2) As explained in our article we use a $50-\mathrm{g}$ glucose load in the oral glucose tolerance test and the criteria of the British Diabetic Association in making the diagnosis of diabetes. In 1971-2 we found diabetes in $0.2 \%$ of all pregnant women seen at King's compared with the figure of $1 \%$ reported by Dr. Drury. ${ }^{1}$ The difference may be partly due to the fact that Dr. Drury uses a 100-g glucose load. It is likely that fetal loss in gestational diabetes is less, or at least no more, than in established cases and it was presumably for this reason that Dr. Drury concluded that it was "imperative to exclude such cases from statistics purporting to show the results of various regimens in the management of pregnancy in the diabetic." If our series had included a larger number of gestational diabetics the results in terms of fetal survival would presumably have been no worse than they actually were. We think therefore that we were justified in our tentative conclusion: "In managing pregnant diabetics it is notoriously easy to be deceived by a run of successes. Nevertheless, other centres too are getting better results than previously, and we think therefore that we are seeing a real improvement."-We are, etc.,

\section{Diabetic Clinic,}

King's Col'ege Hospital,

London S.E.S

Drury, M. I., and Timoney, F. J., fournal of Obstetrics and Gynaecology

\section{Profound Hypothermia with Cardiac Arrest after Immersion}

SIR,-In the case reported by Dr. E. Dominguez de Villota and others (17 November, p. 394) the cardiac asystole and the apparently minimal inhalation of water may have been due to stimulation of a vagal reflex with instantaneous cardiac and respiratory arrest when water entered the nose and/or ears of the child as he fell into the pool, as in the "brides in the bath" murder case of $1915 .^{1-}$ I am, etc.,

Ham Green Hospital,

R. N. WELLS 1 Browne, D. G., and Tullett, E. V., Bermard
Spilsbury. His Life and Cases, p. 70. London,
Harrap, 1952.

\section{General-practitioner Surgeons}

SIR,-Between the 1870s and the formation of the N.H.S. in 1948 a high percentage of the major surgery in this country was performed not in the large centres, but by general practitioners in their capacity as honorary surgeons in their local hospitals. While they depended on their general practice for their livelihood, many hours of their working week were devoted to their unpaid hospital work. They had little clerical assistance-there were dispensers, not secretaries, in those days-and with their double duties they had little time to write papers so that their work has gone largely unrecorded.

Many of them had higher qualifications and were men of considerable intelligence and surgical ability, who for family, financial, or other reasons were unable to apply for the posts that their ability deserved. Consequently, as I know from my own observations, many patients in the smaller industrial towns (particularly in the north) bsnefited from surgery of a very high standard. Among them there were as many "characters" as there were among the surgical giants of their time, but their audiences were small and few people saw their work.

The only pap'r on this subject that I have found in the literature was a plea for cottage-table surgery written in 1914, but feel that there must be other records, either in the histories of local hospitals or in s'ories remembered about the "characters," maybe some of them by now apocryphal. I feel that the labours of those devoted men should be record ${ }^{\circ} d$ before they are entirely forgotten and would be grateful for any help with memories, hospital histories, or other papers which would assist. Any papers forwarded would, of course, be returned as soon as possible.-I am, etc.,

Wardle How,
Brantfell Road,

A. M. MCMASTER

Bowness-on-Windermere

\section{M.P. Pressure}

SIR,-I read Mr. D. F. Thomas's interesting letter (17 November, p. 427) on the subject of M.P. pressure and if it is any comfort to him I can assure him that he is certainly not alone in his experiences. I would also add to M.P.s, local councillors.-I am, etc.,

Hensol Hospital,
Pontyclun, Glam.

$$
\text { D. C. JONES }
$$

\section{Notional Rent}

SIR,-I wonder if many doctors are having similar problems to mine with the assessment of notional rent for surgeries which are within the doctor's residence.

Two years ago I obtained an independent opinion on the rental value of my surgery. This was assessed at $£ 750$ per year. As a result of the new method of reimbursement which came into force on 1 April of this year my notional rent has been assessed at $£ 700$ per year. As this has to stand for the next five years, I will still be obtaining only $£ 700$ per year reimbursement some seven years after the rent was assessed at $£ 750$ per year. It would seem to me that $I$ am being asked to subsidize the Health Service out of my own pocket.-I am, etc.,

London W.11

L. E. WALI

\section{Transfer of Registrars}

SIR,-The discussion on the redistribution of registrars in your leading article (17 November, p. 369) produced the statement that more emergency work will be done by 